Article

\title{
Do Chinese Children Get Enough Micronutrients?
}

\author{
Huijun Wang ${ }^{1}$, Dantong Wang ${ }^{2}$, Yifei Ouyang ${ }^{1}$, Feifei Huang ${ }^{1}$, Gangqiang Ding ${ }^{1}$ \\ and Bing Zhang ${ }^{1, *}$ \\ 1 National Institute for Nutrition and Health, Chinese Center for Disease Control and Prevention, \\ Beijing 100050, China; wanghj128@gmail.com (H.W.); hollyfaye@126.com (Y.O.); fayekobe@163.com (F.H.); \\ dinggq@chinacdc.cn (G.D.) \\ 2 Nestlé Research Center, Lausanne CH-1000, Switzerland; Dantong.Wang@rdls.nestle.com \\ * Correspondence: zzhangb327@aliyun.com; Tel.: +86-10-6623-7008; Fax: +86-10-8313-2909
}

Received: 27 February 2017; Accepted: 12 April 2017; Published: 18 April 2017

\begin{abstract}
The aim of this study was to examine usual daily micronutrient intake of Chinese children based on data from the 2011 China Health and Nutrition Survey. We analyzed data from 4 to 17-year-old participants, who provided dietary data on three consecutive days combined with the household weighing method in 2011. Usual daily intake of each nutrient was estimated using a mixed effects model based on the China Food Composition published in 2009. The means, medians and percentages below Estimated Average Requirements (EAR) were reported for selected micronutrients, including calcium, sodium, potassium, iron, zinc, selenium, vitamin A, thiamine, riboflavin and vitamin $C$. For sodium and potassium, the means and the distribution of intakes were compared to the Adequate Intake (AI) level. The average usual daily intakes of all micronutrients increase with age, and the intakes of boys were found to be higher than girls in the same age group. The average calcium intake increased from $272 \mathrm{mg}$ /day in 4-6 years to $391 \mathrm{mg} /$ day in 14-17 years, but the percentage of inadequate calcium intake remained very high $(>96 \%)$. The prevalence of inadequacy of calcium was the highest among the mineral nutrients reported in this study. As the requirements of micronutrients increased with age, the percentage of subjects with inadequate intake increased in the 11-17 years age groups. Among 14-17 years group, the percentages of study participants with dietary intakes of calcium, iron, zinc, selenium, vitamin $\mathrm{A}$, thiamine, riboflavin and vitamin $\mathrm{C}$ below the EAR were $96.8 \%, 18.8 \%, 37.6 \%, 72.8 \%, 36.8 \%, 91.8 \%$. 85.9\% and 75.5\%, respectively. Among $11-13$ years group, the percentages of study participants with dietary intakes of iron, zinc and vitamin A below the EAR were $23.5 \%, 41.5 \%$, and $41.6 \%$, respectively. Thus, micronutrient deficiency is a problem in Chinese children. Nutrition education and intervention programs are needed to address these nutritional gaps.
\end{abstract}

Keywords: micronutrients; inadequacies; usual daily intake; China

\section{Introduction}

Deficiencies of micronutrients are prevalent among children in developing as well as some developed countries [1-4]. Low micronutrient intake may link to long-term health risks [5-7]. Recent European studies have suggested that substantial numbers of European children might be at risk due to inadequate intake of micronutrients [4,8]. China's dietary changes are enormous $[9,10]$, and the shifts in foods consumed and eating behaviors will continue to accelerate [11]. Recent shifts toward increased snacking [12], away-from-home eating [13], and modern packaged processed foods [14] present dietary challenges in the younger Chinese generations. Low consumption of vegetables, fruits [15], and dairy products [16] affect the nutrition status of children. It is common to see problems of underweight, stunting and micronutrient deficiencies in parallel with an increasing prevalence of overweight and obesity in Chinese children and adolescents. The public health and nutrition policy 
in China has been focused on providing an adequate dietary supply to decrease the prevalence of malnutrition in Chinese children [17]. However, it is still unclear how many Chinese children meet the recommended intakes of micronutrients at the national level.

The most recent Chinese Dietary Reference Intakes (DRIs) were published in 2013 [18]. The DRIs allow for a comparison between daily intakes and recommendations to assess the adequacy level of macro- and micronutrient intake. The China Health and Nutrition Survey (CHNS) is a longitudinal study starting from 1991; food intake data were collected using 24-h recalls on three consecutive days, combined with the household weighing method [19]. Based on CHNS dietary intake data collected in 2011, we examined micronutrient intakes from childhood to adolescence to answer the question: Do Chinese children get enough micronutrients?

\section{Materials and Methods}

\subsection{CHNS and Study Subjects}

This study was based on data from the CHNS, an ongoing longitudinal survey that has been conducted in 1991, 1993, 1997, 2000, 2004, 2006, 2009 and 2011. It was designed to provide a representative sample of households in China by geographical location, level of economic development and use of public resources. The survey focused on examining household- and individual-level socio-demographic factors, diet, physical activity, health status and behavior changes. Detailed information can be found on the project website. We analyzed data from 4- to 17-year-old participants, in total 1905 children who had diet data on three consecutive days in 2011, and stratified the data by gender and age.

\subsection{CHNS Dietary Measurement Methods}

Individual dietary data for three consecutive days (two weekdays and one weekend day) were recorded for all household members 2 years and older. This was achieved by asking each individual, except children younger than 12 years, to report all food consumed at home and away from home in the past $24 \mathrm{~h}$. For children younger than 12 years, the mother or a caregiver who handled food preparation and feeding in the household was asked to recall the children's food consumption. Using food models and picture aids, trained field interviewers recorded the type of food, amount, and type of meal and place of consumption of all food items during the past $24 \mathrm{~h}$. Household edible oils, sugar and salt consumption were determined on a daily basis by calculating the changes in home food inventory by weighing [19]. Dietary intake data were derived from 24-h recalls on three consecutive days, combined with the household weighing method. Food recalls were coded and analyzed to calculate nutrient intakes using the Chinese Food Composition Tables published in 2009 [20]. We reported the results on the intake of key micronutrients, including calcium, sodium, potassium, iron, zinc, selenium, vitamin A, thiamine, riboflavin and vitamin C.

\subsection{Micronutrient Analysis}

The estimated average requirement (EAR) cut-point method was used to estimate the proportion of individuals in the group at the risk of having inadequate micronutrient intakes [21-23]. For sodium and potassium, where the EARs for Chinese children have not yet been established due to insufficient information, the means and distribution of intakes were compared to the Adequate Intake (AI) level. If a group has a mean or median intake at or above the AI, there is a low prevalence of low intake levels. If the mean or median is less than the AI, no inferences about the prevalence of low intake levels were made [21,23]. Appendix A Table A1 provides the EAR or AI for each nutrient by life stage group [18]. 


\subsection{Usual Daily Intake Estimation}

Usual daily intake is defined as the long-run average daily intake of a dietary component by an individual. Usual daily intake of each nutrient was estimated by the mixed effects model and quantile estimation procedure, developed at the National Cancer Institute (NCI). It is one of the statistical procedures for estimating the usual intake distribution from repeated 24-h recalls [24,25]. A separate model was created for each nutrient.

\subsection{Statistical Analysis}

In our analysis, micronutrient intake was assessed in four age groups of girls and boys (aged 4 to 6 years, 7 to 10 years, 11 to 13 years and 14 to 18 years). Continuous variables were expressed as the means, median, 25th percentile and 75th percentile (P25, P75), whereas categorical variables were expressed as percentages (\%). Statistical analysis was done with SAS 9.2 (SAS Institute Inc., Cary, NC, USA).

\section{Results}

\subsection{Characteristics of the Study Subjects}

As shown in Table 1, in total 1905 children aged 4 to 17 years were included in the study. The average age was 8.5 and $51.8 \%$ of the subjects were boys.

\subsection{Characteristics of the Study Subjects}

Table 2 summarizes the mean and selected percentiles of usual dietary intakes, and the percentages of children with inadequate nutrient intakes of calcium, iron, zinc and selenium. Average usual dietary intakes of these minerals were found to increase with age and the intakes of boys were slightly higher than girls in the same age group. The calcium intake increased from $272 \mathrm{mg} /$ day in the 4-6 years group to $391 \mathrm{mg} /$ day in the 14-17 years group, but the percentage of inadequate calcium intake remained very high $(>96 \%)$ in all groups. As iron intake increased with age among boys, the percentage of inadequate iron intake decreased. Although iron intake also increased with age in girls, due to the increasing dietary iron requirements, the percentage of inadequate iron intake also increased with age in girls. The zinc intake increased from $6.3 \mathrm{mg} /$ day in the $4-6$ years group to $10.0 \mathrm{mg} / \mathrm{day}$ in the 14-17 years group, and the percentage of inadequate zinc intake was higher in girls than in boys. The intake of selenium increased with age from $27.0 \mathrm{mg} /$ day (4-6 years) to $45.6 \mathrm{mg} /$ day (14-17 years). However since the requirements for dietary selenium also increased with age, the prevalence of inadequate selenium intake was also higher among older children (at about $50 \%$ in the $4-6$ years group and $72.8 \%$ in the $14-17$ years group).

Usual intakes of both sodium and potassium increased with age, and the intakes of boys were a little higher than girls in the same age group (Table 3). The mean and median intakes of sodium were much higher than the AI for each respective age group. For example, the median of sodium in the 14-17 years group, $4330 \mathrm{mg} /$ day, was much higher than AI of $1600 \mathrm{mg} /$ day. On the contrary, the mean and median intakes of potassium were less than the AI for each respective age group. The gaps between the recommendation and the mean and median intakes grew wider as age increased.

The average and selected percentiles of usual dietary intakes of vitamin A, thiamine (vitamin B1), riboflavin (vitamin B2) and vitamin C are shown in Table 4. Average intakes of these vitamins were found to increase with age, and the intakes in boys were higher than in girls in the same age group. As the requirements of vitamin $\mathrm{A}$, thiamine, riboflavin and vitamin $\mathrm{C}$ increase as children get older, the percentage of subjects with inadequate intake also increased with age. In the 14-17 years group, the percentage of study participants with dietary intakes of vitamin A, thiamine, riboflavin and vitamin $C$ below the EAR were $36.8 \%, 91.8 \%$. $85.9 \%$ and $75.5 \%$, respectively. In the $11-13$ years group, the percentages of study participants with dietary intakes of vitamin $\mathrm{A}$, thiamine, riboflavin and vitamin $C$ below the EAR were $41.6 \%, 89.1 \%, 83.7 \%$ and $69.0 \%$, respectively. 
Table 1. Characteristics of the study subjects. SD, standard deviation.

\begin{tabular}{lccc}
\hline \multirow{2}{*}{ Items } & \multicolumn{2}{c}{ Gender } & \multirow{2}{*}{ Total } \\
\cline { 2 - 3 } & Boys & Girls & \\
\hline Age (years, Mean \pm SD) & $8.0 \pm 4.9$ & $8.5 \pm 4.8$ & $8.2 \pm 4.9$ \\
$4-6$ & $53.1 \%$ & $46.9 \%$ & 461 \\
$7-10$ & $50.2 \%$ & $49.8 \%$ & 623 \\
$11-13$ & $53.8 \%$ & $46.2 \%$ & 405 \\
$14-17$ & $50.7 \%$ & $49.3 \%$ & 416 \\
\hline Urban & 51.7 & 48.3 & 755 \\
Rural & 50.3 & 49.7 & 1150 \\
Total & $51.8 \%$ & $48.2 \%$ & 1905 \\
\hline
\end{tabular}

Table 2. Usual daily intake and proportion below the estimated average requirements (EAR) for calcium, iron, zinc and selenium among Chinese children.

\begin{tabular}{|c|c|c|c|c|c|c|c|c|c|c|c|c|}
\hline \multirow{3}{*}{ Items } & \multicolumn{12}{|c|}{ Nutrients } \\
\hline & \multicolumn{3}{|c|}{ Calcium (mg/Day) } & \multicolumn{3}{|c|}{ Iron (mg/Day) } & \multicolumn{3}{|c|}{ Zinc (mg/Day) } & \multicolumn{3}{|c|}{ Selenium (mg/Day) } \\
\hline & Mean & $\begin{array}{c}\text { Median } \\
\text { (P25, P75) }\end{array}$ & $\begin{array}{c}\text { Below } \\
\text { EAR (\%) }\end{array}$ & Mean & $\begin{array}{c}\text { Median } \\
\text { (P25, P75) }\end{array}$ & $\begin{array}{c}\text { Below } \\
\text { EAR (\%) }\end{array}$ & Mean & $\begin{array}{c}\text { Median } \\
\text { (P25, P75) }\end{array}$ & $\begin{array}{c}\text { Below } \\
\text { EAR (\%) }\end{array}$ & Mean & $\begin{array}{c}\text { Median } \\
\text { (P25, P75) }\end{array}$ & $\begin{array}{c}\text { Below } \\
\text { EAR (\%) }\end{array}$ \\
\hline \multicolumn{13}{|l|}{ Boys } \\
\hline $4-6$ & 273 & $237(164,338)$ & 97.1 & 12.4 & $11.7(9.1,14.9)$ & 7.8 & 6.7 & $6.3(5.0,8.0)$ & 18.9 & 27.6 & $25.7(18.7,34.3)$ & 47.3 \\
\hline $7-10$ & 314 & $273(190,389)$ & 97.9 & 15.6 & $14.6(11.5,18.6)$ & 14.6 & 8.0 & $7.6(6.0,9.6)$ & 23.9 & 34.2 & $32.4(24.1,42.7)$ & 57.5 \\
\hline $11-13$ & 378 & $328(229,469)$ & 98.1 & 19.0 & $17.8(14.0,22.6)$ & 9.2 & 9.5 & $9.0(7.1,11.3)$ & 39.3 & 40.6 & $37.9(28.5,49.7)$ & 66.1 \\
\hline $14-17$ & 428 & $374(261,532)$ & 96.2 & 21.5 & $20.3(15.9,25.7)$ & 7.2 & 11.2 & $10.7(8.5,13.4)$ & 39.0 & 46.8 & $44.1(33.3,57.2)$ & 62.9 \\
\hline \multicolumn{13}{|l|}{ Girls } \\
\hline $4-6$ & 269 & $235(160,339)$ & 97.5 & 11.4 & $10.7(8.4,13.6)$ & 11.4 & 5.9 & $5.6(4.4,7.1)$ & 29.7 & 26.1 & $23.8(16.9,32.8)$ & 53.9 \\
\hline $7-10$ & 312 & $274(188,390)$ & 97.9 & 14.3 & $13.5(10.6,17.0)$ & 20.0 & 7.4 & $7.1(5.6,8.9)$ & 30.4 & 29.7 & $27.4(19.7,37.1)$ & 70.6 \\
\hline $11-13$ & 345 & $301(208,430)$ & 98.9 & 16.2 & $15.2(12.0,19.3)$ & 40.4 & 8.4 & $8.0(6.3,10.0)$ & 44.1 & 34.8 & $32.1(23.2,43.2)$ & 78.2 \\
\hline $14-17$ & 360 & $317(218,450)$ & 97.6 & 17.7 & $16.7(13.1,21.0)$ & 30.8 & 8.8 & $8.5(6.7,10.5)$ & 36.1 & 36.8 & $34.2(24.9,45.7)$ & 81.4 \\
\hline \multicolumn{13}{|l|}{ Total } \\
\hline $4-6$ & 272 & $236(163,338)$ & 97.1 & 12.0 & $11.2(8.8,14.3)$ & 9.7 & 6.3 & $6.0(4.6,7.6)$ & 24.2 & 27.0 & $24.8(17.8,33.7)$ & 50.8 \\
\hline $7-10$ & 313 & $273(189,390)$ & 97.9 & 14.9 & $14.0(11.0,17.8)$ & 17.7 & 7.7 & $7.3(5.7,9.2)$ & 27.8 & 32.2 & $29.8(21.6,39.9)$ & 64.3 \\
\hline $11-13$ & 364 & $317(219,454)$ & 98.6 & 17.4 & $16.6(13.0,21.2)$ & 23.5 & 9.0 & $8.6(6.7,10.8)$ & 41.5 & 38.1 & $35.3(25.8,47.1)$ & 71.4 \\
\hline $14-17$ & 391 & $342(237,488)$ & 96.8 & 19.5 & $18.3(14.3,23.3)$ & 18.8 & 10.0 & $9.5(7.5,11.9)$ & 37.6 & 45.6 & $38.7(28.6,51.3)$ & 72.8 \\
\hline
\end{tabular}


Table 3. Mean and selected percentiles of usual daily sodium and potassium intakes among Chinese children.

\begin{tabular}{ccccccccc}
\hline & \multicolumn{8}{c}{ Nutrients } \\
\cline { 2 - 9 } Items & \multicolumn{3}{c}{ Sodium (mg/Day) } & \multicolumn{5}{c}{ Potassium (mg/Day) } \\
\cline { 2 - 9 } & Mean & P25 & Median & P75 & Mean & P25 & Median & P75 \\
\hline Boys & & & & & & & & \\
\hline $4-6$ & 3267 & 1572 & 2782 & 4400 & 1066 & 748 & 987 & 1289 \\
$7-10$ & 39,786 & 2082 & 3463 & 5302 & 1318 & 929 & 1217 & 1586 \\
$11-13$ & 4586 & 2502 & 40037 & 6055 & 1567 & 1110 & 1451 & 2187 \\
$14-17$ & 5150 & 2923 & 4607 & 6769 & 1776 & 1264 & 1652 & 2146 \\
\hline Girls & & & & & & & & \\
\hline $4-6$ & 3022 & 1592 & 2619 & 4016 & 998 & 702 & 927 & 1214 \\
$7-10$ & 3632 & 2012 & 3191 & 4743 & 1208 & 858 & 1125 & 1460 \\
$11-13$ & 3799 & 2016 & 3329 & 4948 & 1307 & 989 & 1287 & 1674 \\
$14-17$ & 4598 & 2690 & 4124 & 5961 & 1387 & 1021 & 1287 & 1732 \\
\hline Total & & & & & & & & \\
\hline $4-6$ & 3148 & 1591 & 2691 & 4189 & 1035 & 725 & 957 & 1254 \\
$7-10$ & 3787 & 2032 & 3315 & 4995 & 1259 & 887 & 1169 & 1523 \\
$11-13$ & 4228 & 2323 & 3721 & 5563 & 1487 & 1047 & 1378 & 1802 \\
$14-17$ & 4849 & 2781 & 4330 & 6344 & 1593 & 1127 & 1480 & 1930 \\
\hline
\end{tabular}

Table 4. Usual daily intake and proportion below the EAR for vitamin A, thiamine, riboflavin and vitamin C among Chinese children.

\begin{tabular}{|c|c|c|c|c|c|c|c|c|c|c|c|c|}
\hline \multirow{3}{*}{ Items } & \multicolumn{12}{|c|}{ Nutrients } \\
\hline & \multicolumn{3}{|c|}{ Vitamin A ( $\mu \mathrm{g} /$ Day $)$ * } & \multicolumn{3}{|c|}{ Thiamine (mg/Day) } & \multicolumn{3}{|c|}{ Riboflavin (mg/Day) } & \multicolumn{3}{|c|}{ Vitamin C (mg/Day) } \\
\hline & Mean & Median (P25, P75) & Below EAR (\%) & Mean & Median (P25, P75) & Below EAR (\%) & Mean & Median (P25, P75) & Below EAR (\%) & Mean & Median (P25, P75) & Below EAR (\%) \\
\hline \multicolumn{13}{|l|}{ Boys } \\
\hline $4-6$ & 555 & $443(263,714)$ & 24.6 & 0.6 & $0.5(0.4,0.7)$ & 61.6 & 0.6 & $0.5(0.4,0.7)$ & 61.9 & 45.2 & $39.7(25.2,58.8)$ & 50.5 \\
\hline 7-10 & 645 & $520(315,831)$ & 30.8 & 0.6 & $0.6(0.5,0.8)$ & 76.6 & 0.7 & $0.6(0.4,0.8)$ & 74.2 & 55.1 & $49.0(32.2,71.1)$ & 57.9 \\
\hline $11-13$ & 734 & $592(362,941)$ & 38.6 & 0.8 & $0.7(0.6,0.9)$ & 87.9 & 0.8 & $0.7(0.5,0.9)$ & 85.6 & 67.9 & $61.0(41.2,86.8)$ & 65.0 \\
\hline $14-17$ & 872 & $715(441,1121)$ & 39.3 & 0.9 & $0.8(0.7,1.1)$ & 89.7 & 0.9 & $0.8(0.6,1.1)$ & 86.8 & 70.7 & $64.0(43.5,90.4)$ & 70.8 \\
\hline \multicolumn{13}{|l|}{ Girls } \\
\hline $4-6$ & 487 & $407(250,635)$ & 26.7 & 0.5 & $0.5(0.3,0.6)$ & 75.9 & 0.5 & $0.5(0.3,0.6)$ & 70.3 & 40.6 & $35.6(22.6,53.2)$ & 57.4 \\
\hline 7-10 & 604 & $511(321,778)$ & 30.3 & 0.6 & $0.6(0.4,0.7)$ & 82.7 & 0.6 & $0.6(0.4,0.7)$ & 79.9 & 54.8 & $49.1(32.6,70.4)$ & 58.2 \\
\hline $11-13$ & 582 & $488(306,749)$ & 45.1 & 0.7 & $0.6(0.5,0.8)$ & 90.6 & 0.7 & $0.6(0.5,0.8)$ & 81.5 & 59.5 & $53.3(35.7,76.2)$ & 73.9 \\
\hline $14-17$ & 688 & $588(373,887)$ & 34.3 & 0.7 & $0.7(0.5,0.8)$ & 94.0 & 0.7 & $0.7(0.5,0.9)$ & 85.0 & 61.3 & $55.5(37.3,78.8)$ & 79.6 \\
\hline \multicolumn{13}{|l|}{ Total } \\
\hline $4-6$ & 522 & $426(259,674)$ & 25.3 & 0.5 & $0.5(0.4,0.6)$ & 68.3 & 0.5 & $0.5(0.4,0.7)$ & 66.0 & 43.0 & $37.6(24.0,55.9)$ & 53.9 \\
\hline $7-10$ & 624 & $518(318,804)$ & 30.6 & 0.6 & $0.6(0.4,0.8)$ & 79.4 & 0.6 & $0.6(0.4,0.8)$ & 77.1 & 54.9 & $49.1(32.3,70.7)$ & 58.1 \\
\hline $11-13$ & 661 & $547(337,853)$ & 41.6 & 0.7 & $0.7(0.5,0.9)$ & 89.1 & 0.7 & $0.7(0.5,0.9)$ & 83.7 & 64.1 & $57.7(38.6,82.3)$ & 69.0 \\
\hline $14-17$ & 769 & $645(403,994)$ & 36.8 & 0.8 & $0.7(0.6,0.9)$ & 91.8 & 0.8 & $0.7(0.5,1.0)$ & 85.9 & 65.7 & $59.3(40.0,84.3)$ & 75.5 \\
\hline
\end{tabular}

* $\mu \mathrm{g}$ retinol activity equivalent per day. 


\section{Discussion}

This is the first study that used usual nutrient intake estimations and applied the EAR cut-point method to assess the adequacy of micronutrient intakes among 4 to 17-year-old children and adolescents in China [23,24]. Previously, researchers reported low intakes of calcium [26], iron [27] and vitamin C [28] in Chinese children based on average intake values, but no prevalence of inadequate intake was calculated. In one study, the usual nutrient intakes and prevalence of inadequate intakes were estimated in adults based on the data from China National Nutrition and Health Survey in 2002. Results highlighted the inadequate intakes of some micronutrients, such as calcium, zinc, selenium, thiamine and riboflavin [29]. The results of this study are consistent with previous reports [26-28].

Although the dietary patterns in China have changed in the past 20 years [30], Chinese children do not get enough micronutrients. The present study showed that, compared to the current reference values, there was a substantial percentage of Chinese children who had low intakes for calcium, zinc, selenium, vitamin A, thiamine, riboflavin and vitamin $\mathrm{C}$. The prevalence of inadequate nutrient intakes ranged from $9.7 \%$ in the $4-6$ years group for iron to $98.6 \%$ in the $11-13$ years group for calcium. For the majority of nutrients analyzed in this study, nutrient intake increased with age, which is to be expected, since older children consume more food and have higher energy intakes [31]. However, the prevalence of inadequacy also increased because older children have increased requirements growing up.

The prevalence of inadequate calcium intake was the highest among the mineral nutrients analyzed in this study. The main reason for this is likely the low consumption of dairy products, which is the most important food source of dietary calcium in Chinese children [16]. Although the percentage of inadequate iron was the lowest among the mineral nutrients, we should pay attention to girls' intake. For girls over 10 years old, the iron EAR cut-points were higher than boys while the intake level was lower, thus the prevalence of inadequacy of iron showed a significant gender difference. Among 11-13 year olds, the prevalence of inadequate iron intake in girls was 31.2 points higher than in boys. There were also high proportions of children and adolescents who had intakes below the EAR for zinc and selenium, ranging from $24.2 \%$ to $41.5 \%$ for zinc and from $50.8 \%$ to $72.8 \%$ for selenium, respectively. Compared with the children in European countries, the prevalence of calcium, iron, selenium and zinc inadequacies were much higher in Chinese children. For example, in children aged 4-10 years in European countries, calcium intakes ranged from $563 \mathrm{mg} /$ day in Polish girls to $1106 \mathrm{mg}$ / day in Danish boys, with only $32 \%$ of the girls and $28 \%$ of the boys having calcium intakes below the EAR [8,32]. Compared with the children in the U.S., based on America, National Health and Nutrition Examination Survey (NHANES) 2007-2010, calcium intakes were much higher than Chinese children; calcium intakes were $975 \mathrm{mg} /$ day and $1047 \mathrm{mg} /$ day in U.S. children aged 4-8 years and 9-18 years, respectively. Calcium inadequacies were much lower than Chinese children; in U.S. children, only $5.8 \%$ of the boys aged $4-8$ years showed calcium intakes below the EAR, but the percentage was also very high in some age groups, for example, the percent was $81.9 \%$ of the girls aged $9-18$ years in U.S. [33].

The mean and median intakes of potassium were below the AI, but no clear conclusions can be drawn about the prevalence of low intakes [21]. We found that the gap between potassium mean intakes and $\mathrm{AI}$ increased as age increased. In European countries, potassium intakes among children were much higher than in Chinese children. In 4-10 year olds in European countries, the mean intake ranged from $2077 \mathrm{mg} /$ day (Dutch girls aged 4-6 years) to $3044 \mathrm{mg} /$ day (Dutch boys aged 7-10 years); the mean intake among 11-17 year olds ranged from $2148 \mathrm{mg} /$ day (UK girls) to $3899 \mathrm{mg} /$ day (German boys) [32]. In the U.S., although less than $2 \%$ of Americans in any age-gender group consume at or above the AI for potassium, potassium intakes among children were much higher than in Chinese children. Based on NHANES 2007-2010, the means of potassium intake were $2049 \mathrm{mg}$ /day in those aged 4-8 years and $2261 \mathrm{mg} /$ day in those aged 9-18 years [33]. Sodium intakes were much higher than the AI for each respective age group. There is a low prevalence of low intake levels, but we should also pay attention to the health effects of high sodium intakes. 
The intake levels of thiamine and riboflavin found in children and adolescents in this study were very similar to the reported intake distribution of adults in China, based on the China National Nutrition and Health Survey in 2002. The prevalence of inadequacies of both vitamins was over $80 \%$ [29]. Cereal products are one of the most important sources of thiamine, but the consumption of cereal products has decreased in Chinese children over the past twenty years [30]. Perhaps this is one of the main reasons for the increasing prevalence of inadequate thiamine intake. In children aged 4-17 years European countries, inadequate intakes of thiamine and riboflavin are low. The highest proportion of intakes below the EAR was for thiamine ( $8 \%$ in girls age 4-10 years from Poland), and for riboflavin (26\% observed in girls aged 11-17 years in UK) [32]. In China, high percentages of children and adolescents had inadequate intakes for vitamin $C$ and vitamin $A$, ranging from $53.9 \%$ to $75.5 \%$ (vitamin C) and from $25.3 \%$ to $36.8 \%$ (vitamin A), and the proportions increased with age. The percentages of inadequate vitamin $\mathrm{C}$ intake were higher in Chinese children than among European children ( $0.2 \%$ to $8.0 \%$ in European children). The proportion of intakes below the EAR for vitamin A varied among the European countries, ranging from $2 \%$ for Germany to $30 \%$ for UK children aged 11-17 years [32]. In the U.S., vitamin A and riboflavin deficiencies were not widespread concerns [33].

Greater dietary diversity has been associated with micronutrient status in many studies [34,35]. Improving diet variety and quality to meet the nutrient intake recommendations may be an effective approach to reduce health risks in Chinese children. Geographic location and socioeconomic status vary a lot in China, and this could have an important impact on dietary habits, food quality, and micronutrient intake. Further studies are needed to discover the differences and provide evidence for developing community-specific strategies to improve micronutrient intake.

\section{Conclusions}

Based on the usual daily micronutrient intake of Chinese children which came from the 2011 China Health and Nutrition Survey, Chinese children do not get enough micronutrients. The present study showed that, compared to the current reference values, there was a substantial percentage of Chinese children who had low intakes for calcium, zinc, selenium, vitamin A, thiamine, riboflavin and vitamin C. micronutrient deficiency is a problem in Chinese children. Nutrition education and intervention programs are needed to address these nutritional gaps.

\section{Limitations}

Dietary supplement consumption data were not collected in CHNS 2011, but the effect is likely to be small. To our knowledge, there are few studies focused on dietary supplement use in the China. One study indicated that the intake rate of vitamin and mineral dietary supplements among 3 to 12-year-old children in seven cities and two counties ranged widely, from $27.46 \%$ for calcium to $4.87 \%$ for iron [36]. Rates of supplement use were lower compared to other countries, for example in Korea, where dietary supplement use is $49.5 \%-54.2 \%$ among 1 to 6-year-olds [37] and $28.5 \%$ in 9 to 18 -year-olds [38]. One-third of 4 to 18-year-old children in the United States were reported to use dietary supplements from 2003 to 2006 [39]. So, it is possible that this study slightly underestimated vitamin and mineral intakes in Chinese children. Another limitation is the risk of under-reporting. A European study assessed the impacts of under-reporting micronutrient intakes. After excluding under-reporters, the mean intake increased slightly in some age groups, but the inadequate intake level did not change substantially [32]. Therefore, we estimate the impact of potential under-reporting could be limited.

Acknowledgments: This research uses data from China Health and Nutrition Survey (CHNS). We thank the National Institute for Nutrition and Health, China Center for Disease Control and Prevention, Carolina Population Center, the University of North Carolina at Chapel Hill, the NIH (R01-HD30880, DK056350, and R01-HD38700) and the Fogarty International Center, NIH for financial support for the CHNS data collection and analysis files from1989 to 2011.

Author Contributions: Huijun Wang, Dantong Wang and Bing Zhang contributed to the initial design of the analysis. Huijun Wang contributed to the analysis. All authors contributed to the interpretation of data analysis results and wrote the first draft of the manuscript. Dangtong Wang revised the manuscript. 
Conflicts of Interest: The authors have no conflict of interest. Financial disclosure: This research uses data from China Health and Nutrition Survey (CHNS). NIH provided financial support for the CHNS data collection. This analysis was sponsored by the Nestlé Research Center (NESTEC, Ltd.), Lausanne, Switzerland.

\section{Appendix A}

Table A1. EARs or AIs for selected micronutrients for Chinese children *.

\begin{tabular}{|c|c|c|c|c|c|c|c|c|c|c|}
\hline & Calcium & Iron & Zinc & Selenium & Sodium & Potassium & Vitamin A & Thiamine & Riboflavin & Vitamin C \\
\hline Items & $\begin{array}{c}\text { EAR } \\
\text { (mg/Day) }\end{array}$ & $\begin{array}{c}\text { EAR } \\
\text { (mg/Day) }\end{array}$ & $\begin{array}{c}\text { EAR } \\
\text { (mg/Day) }\end{array}$ & $\begin{array}{c}\text { EAR } \\
\text { (mg/Day) }\end{array}$ & $\begin{array}{c}\text { AI } \\
\text { (mg/Day) }\end{array}$ & $\begin{array}{c}\text { AI } \\
\text { (mg/Day) }\end{array}$ & $\begin{array}{c}\text { EAR } \\
(\mu \mathrm{g} / \text { Day }) * *\end{array}$ & $\begin{array}{c}\text { EAR } \\
\text { (mg/Day) }\end{array}$ & $\begin{array}{c}\text { EAR } \\
\text { (mg/Day) }\end{array}$ & $\begin{array}{c}\text { EAR } \\
\text { (mg/Day) }\end{array}$ \\
\hline \multicolumn{11}{|l|}{ Boys } \\
\hline $4-6$ & 650 & 7 & 4.6 & 25 & 900 & 1200 & 260 & 0.6 & 0.6 & 40 \\
\hline $7-10$ & 800 & 10 & 5.9 & 35 & 1200 & 1500 & 360 & 0.8 & 0.8 & 55 \\
\hline $11-13$ & 1000 & 11 & 8.2 & 45 & 1400 & 1900 & 480 & 1.1 & 1.1 & 75 \\
\hline \multicolumn{11}{|l|}{ Girls } \\
\hline $4-6$ & 650 & 7 & 4.6 & 25 & 900 & 1200 & 260 & 0.6 & 0.6 & 40 \\
\hline $7-10$ & 800 & 10 & 5.9 & 35 & 1200 & 1500 & 360 & 0.8 & 0.8 & 55 \\
\hline $11-13$ & 1000 & 14 & 7.6 & 45 & 1400 & 1900 & 450 & 1.0 & 0.9 & 75 \\
\hline $14-17$ & 800 & 14 & 6.9 & 50 & 1600 & 2200 & 450 & 1.1 & 1.0 & 85 \\
\hline
\end{tabular}

* Chinese Dietary Reference Intakes (DRIs) 2013 [18]. ${ }^{* *} \mu \mathrm{g}$ retinol activity equivalent per day. EARs: Estimated Average Requirements; AI: Adequate Intake.

\section{References}

1. Arsenault, J.E.; Yakes, E.A.; Islam, M.M.; Hossain, M.B.; Ahmed, T.; Hotz, C.; Lewis, B.; Rahman, A.S.; Jamil, K.M.; Brown, K.H. Very low adequacy of micronutrient intakes by young children and women in rural bangladesh is primarily explained by low food intake and limited diversity. J. Nutr. 2013, 143, $197-203$. [CrossRef] [PubMed]

2. Korkalo, L.; Freese, R.; Alfthan, G.; Fidalgo, L.; Mutanen, M. Poor micronutrient intake and status is a public health problem among adolescent Mozambican girls. Nutr. Res. 2015, 35, 664-673. [CrossRef] [PubMed]

3. Affenito, S.G.; Thompson, D.R.; Franko, D.L.; Striegel-Moore, R.H.; Daniels, S.R.; Barton, B.A.; Schreiber, G.B.; Schmidt, M.; Crawford, P.B. Longitudinal assessment of micronutrient intake among african-american and white girls: The national heart, lung, and blood institute growth and health study. J. Am. Diet. Assoc. 2007, 107, 1113-1123. [CrossRef] [PubMed]

4. Manios, Y.; Moschonis, G.; Mavrogianni, C.; Bos, R.; Singh-Povel, C. Micronutrient intakes among children and adults in Greece: The role of age, sex and socio-economic status. Nutrients 2014, 6, 4073-4092. [CrossRef] [PubMed]

5. $\quad$ Black, R.E.; Allen, L.H.; Bhutta, Z.A.; Caulfield, L.E.; de Onis, M.; Ezzati, M.; Mathers, C.; Rivera, J.; Maternal and Child Undernutrition Study Group. Maternal and child undernutrition: Global and regional exposures and health consequences. Lancet 2008, 371, 243-260. [CrossRef]

6. Winkleby, M.A.; Robinson, T.N.; Sundquist, J.; Kraemer, H.C. Ethnic variation in cardiovascular disease risk factors among children and young adults: Findings from the third national health and nutrition examination survey, 1988-1994. JAMA 1999, 281, 1006-1013. [CrossRef] [PubMed]

7. Bhargava, A. Protein and micronutrient intakes are associated with child growth and morbidity from infancy to adulthood in the Philippines. J. Nutr. 2016, 146, 133-141. [CrossRef] [PubMed]

8. Kaganov, B.; Caroli, M.; Mazur, A.; Singhal, A.; Vania, A. Suboptimal micronutrient intake among children in Europe. Nutrients 2015, 7, 3524-3535. [CrossRef] [PubMed]

9. Popkin, B.M.; Du, S. Dynamics of the nutrition transition toward the animal foods sector in China and its implications: A worried perspective. J. Nutr. 2003, 133, 3898S-3906S. [PubMed]

10. Wang, Z.H.; Zhai, F.Y.; Wang, H.J.; Zhang, J.G.; Du, W.W.; Su, C.; Zhang, J.; Jiang, H.R.; Zhang, B. Secular trends in meat and seafood consumption patterns among Chinese adults, 1991-2011. Eur. J. Clin. Nutr. 2015, 69, 227-233. [CrossRef] [PubMed]

11. Wang, Z.; Zhai, F.; Du, S.; Popkin, B. Dynamic shifts in Chinese eating behaviors. Asia Pac. J. Clin. Nutr. 2008, 17, 123-130. [PubMed] 
12. Wang, Z.; Zhai, F.; Zhang, B.; Popkin, B.M. Trends in Chinese snacking behaviors and patterns and the social-demographic role between 1991 and 2009. Asia Pac. J. Clin. Nutr. 2012, 21, 253-262. [PubMed]

13. Du, W.W.; Su, C.; Wang, H.J.; Wang, Z.H.; Zhang, J.G.; Zhang, J.; Jiang, H.R.; Zhang, Y.G.; Zhang, B. Situation on 'eating out' and its related risk factors among 1013 Chinese adults in 3 provinces. Zhonghua Liu Xing Bing Xue Za Zhi 2013, 34, 1159-1163. [PubMed]

14. Zhang, J.; Huang, F.; Wang, H.; Zhai, F.; Zhang, B. Energy and macronutrients intake from pre-packaged foods among urban residents. Wei Sheng Yan Jiu 2015, 44, 344-346. [PubMed]

15. Wang, Z.H.; Zhang, B.; Wang, H.J.; Zhang, J.G.; Du, W.W.; Su, C.; Zhang, J.; Jiang, H.R.; Zhai, F.Y. Trend in vegetable and fruit intake among Chinese children and adolescents aged 6 to 17 years from 1991 to 2009 and related socio-demographic factors. Zhonghua Liu Xing Bing Xue Za Zhi 2013, 34, 863-868. [PubMed]

16. Du, W.W.; Zhang, B.; Wang, H.J.; Wang, Z.H.; Su, C.; Zhai, F.Y. Milk consumption and effects on dietary nutrients and growth status among chinese children in nine provinces (autonomous region) from 1991 to 2006. Zhonghua Yu Fang Yi Xue Za Zhi 2011, 45, 313-317. [PubMed]

17. Ma, G. The nutrition status of students in China and the relevant nutrition improvement policy. Chin. J. Sch. Health 2013, 34, 641-643.

18. Cheng, Y. The introduction of Chinese dietary reference intakes 2013 Acta Nutr. Sin. 2014, 36, $313-317$.

19. Zhang, B.; Zhai, F.Y.; Du, S.F.; Popkin, B.M. The China health and nutrition survey, 1989-2011. Obes. Rev. 2014, 15, 2-7. [CrossRef] [PubMed]

20. Yang, Y.; Wang, G.; Pan, X. China Food Composition; Peking University Medical Press: Beijing, China, 2009.

21. Murphy, S.P.; Poos, M.I. Dietary reference intakes: Summary of applications in dietary assessment. Public Health Nutr. 2002, 5, 843-849. [CrossRef] [PubMed]

22. Kennedy, E.; Meyers, L. Dietary reference intakes: Development and uses for assessment of micronutrient status of women-A global perspective. Am. J. Clin. Nutr. 2005, 81, 1194S-1197S. [PubMed]

23. Murphy, S.P. Using dris for dietary assessment. Asia Pac. J. Clin. Nutr. 2008, 17, 299-301. [PubMed]

24. Tooze, J.A.; Kipnis, V.; Buckman, D.W.; Carroll, R.J.; Freedman, L.S.; Guenther, P.M.; Krebs-Smith, S.M.; Subar, A.F.; Dodd, K.W. A mixed-effects model approach for estimating the distribution of usual intake of nutrients: The NCI method. Stat. Med. 2010, 29, 2857-2868. [CrossRef] [PubMed]

25. Laureano, G.H.; Torman, V.B.; Crispim, S.P.; Dekkers, A.L.; Camey, S.A. Comparison of the ISU, NCI, MSM, and spade methods for estimating usual intake: A simulation study of nutrients consumed daily. Nutrients 2016, 8, 166. [CrossRef] [PubMed]

26. Zhang, J.; Wang, H.J.; Wang, Z.H.; Zhang, J.G.; Du, W.W.; Su, C.; Jiang, H.R.; Zhai, F.Y.; Zhang, B. Trend in dietary calcium intake among chinese children and adolescents aged 4 to 17 years in nine provinces from 1991 to 2009. Zhonghua Liu Xing Bing Xue Za Zhi 2013, 34, 857-862. [PubMed]

27. Liu, A.; Zhang, B.; Wang, H.; Du, W.; Su, C.; Zhai, F. Nutrients intake trend of Chinese population in nine provinces from 1991 to 2009 (VI) zinc intake trend of chinese children aged 7-17 years. Acta Nutr. Sin. 2013, 35, 131-133.

28. Wang, Z.H.; Zhang, B.; Wang, H.J.; Zhang, J.G.; Du, W.W.; Su, C.; Zhang, J.; Zhai, F.Y. Trend in dietary vitamin c intake among Chinese children and adolescents between 1991 and 2009. Zhonghua Yu Fang Yi Xue Za Zhi 2012, 46, 1069-1073. [PubMed]

29. Fan, Y.; Liu, A.; He, Y.; Yang, X.; Xu, G.; Ma, G. Assessment of nutrient adequacy of adult residents in china. Acta Nutr. Sin. 2012, 34, 15-19.

30. Wang, X.; Su, C.; Ouyang, Y.; Li, W.; Zhang, B.; Wang, H. Trends of the Chinese in dietary pattern of children and adolescents in communities at different urbanizaton levels. Acta Nutr. Sin. 2016, 38, 119-123.

31. Zhang, B.; Wang, H.J.; Su, C.; Du, W.W.; Zhang, J.G.; Wang, Z.H.; Zhang, J.; Zhai, F.Y. Trend of energy intake among Chinese children and adolescents in nine provinces from 1989 to 2009. Zhonghua Yu Fang Yi Xue Za Zhi 2012, 46, 1064-1068. [PubMed]

32. Mensink, G.B.; Fletcher, R.; Gurinovic, M.; Huybrechts, I.; Lafay, L.; Serra-Majem, L.; Szponar, L.; Tetens, I.; Verkaik-Kloosterman, J.; Baka, A.; et al. Mapping low intake of micronutrients across Europe. Br. J. Nutr. 2013, 110, 755-773. [CrossRef] [PubMed]

33. Quann, E.E.; Fulgoni, V.L., III; Auestad, N. Consuming the daily recommended amounts of dairy products would reduce the prevalence of inadequate micronutrient intakes in the United States: Diet modeling study based on NHANES 2007-2010. Nutr. J. 2015, 14, 90. [CrossRef] [PubMed] 
34. Steyn, N.P.; Nel, J.; Labadarios, D.; Maunder, E.M.; Kruger, H.S. Which dietary diversity indicator is best to assess micronutrient adequacy in children 1 to 9 years? Nutrition 2014, 30, 55-60. [CrossRef] [PubMed]

35. Allen, L.H. To what extent can food-based approaches improve micronutrient status? Asia Pac. J. Clin. Nutr. 2008, 17, 103-105. [PubMed]

36. Wang, J.; Zhang, Y.; Yong, X.; Zhao, A.; Zheng, Y.; Zhang, Y.-M.; Wang, P. Intake of supplemental vitamin and mineral of Chinese children aged 3-12 years old. Chin. J. Child Health Care 2015, 23, 584-587.

37. Kang, D.S.; Lee, K.S. The status of dietary supplements intake in Korean preschool children: Data from the Korea national health and nutrition examination survey 2010-2012. Pediatr. Gastroenterol. Hepatol. Nutr. 2014, 17, 178-185. [CrossRef] [PubMed]

38. Kang, M.; Kim, D.W.; Lee, H.; Lee, Y.J.; Jung, H.J.; Paik, H.Y.; Song, Y.J. The nutrition contribution of dietary supplements on total nutrient intake in children and adolescents. Eur. J. Clin. Nutr. 2016, 70, 257-261. [CrossRef] [PubMed]

39. Bailey, R.L.; Gahche, J.J.; Lentino, C.V.; Dwyer, J.T.; Engel, J.S.; Thomas, P.R.; Betz, J.M.; Sempos, C.T.; Picciano, M.F. Dietary supplement use in the United States, 2003-2006. J. Nutr. 2011, 141, 261-266. [CrossRef] [PubMed]

(C) 2017 by the authors. Licensee MDPI, Basel, Switzerland. This article is an open access article distributed under the terms and conditions of the Creative Commons Attribution (CC BY) license (http:/ / creativecommons.org/licenses/by/4.0/). 